Conference abstract PDD11

\title{
A New Microemulsion for the Transdermal Delivery of Quercetin
}

\author{
L. MALAJ ${ }^{1}, \underline{\text { V. MARTEnA }}^{2}{ }^{2}$, S. GIOVEnAli ${ }^{2}$, P. DI MARTINo ${ }^{2}$ \\ ${ }^{1}$ University of Tirana, Tirana, Albania \\ ${ }^{2}$ University of Camerino, Camerino, Italy \\ E-mail: piera.dimartino@unicam.it (P. Di Martino).
}

Sci Pharm. 2010; 78: 600

doi:10.3797/scipharm.cespt.8.PDD11

Quercetin is a flavonol with antioxidant properties, exhibiting poor water solubility and transdermal permeation ability. The objective of this study was to formulate a new microemulsion for the transdermal delivery of quercetin based on the use of Transcutol ${ }^{\circledR} \mathrm{P}$ as a solubilizing agent and absorption promoter.

Materials and Methods

Quercetin hydrated (>95\%) was purchased from Sigma-Aldrich (Germany). All the excipients were kindly supplied by Gattefossé (France). The microemulsion was prepared by mixing the water and the lipidic phase under gently and continuous stirring at room temperature. Formulations were characterized for physical stability (centrifugation), pH, viscosity (viscosimeter Rheomat RM 180), internal phase dimensions (optical microscope, Leitz), in vitro transdermal diffusion. For this last experiment, 6 vertical Franz's cells were used. A polypropilen membrane $\left(\right.$ Celgard $^{\circledR}$ k-381) soaked up with Labrafac ${ }^{\circledR}$ lipophile WL1349/CHCl 3 (1:3) was used. The quercetin diffusion was determined by VISspectrophotometry.

Results

The solubility of quercetin was spectrophotometrically determined in different excipients and whose in which it was more soluble were selected.

Through a ternary diagram, the percentages of the following phases were determined: lipidic phase, water phase, ratio surfactant/co-surfactant. The best formulation was: $1 \%$ of quercetin, $16.67 \%$ of water phase with $40 \%$ of Transcutol $^{\circledR} \mathrm{P}, 16.67 \%$ of lipidic phase $\left(\right.$ Labrafil $\left.{ }^{\circledR}\right), 66.67 \%$ S/coS (Labraso $^{\circledR}$, Capryol $^{\circledR}$ 90). The most stable microemulsion was an $\mathrm{O} / \mathrm{W}$ microemulsion, appearing as a yellow transparent liquid, with an internal phase size of 10-50 $\mathrm{nm}$ and a $\mathrm{pH}$ of 5.0. The dynamic viscosity was $0.068 \pm 0.003 \mathrm{~Pa}^{*} \mathrm{~s}$. The quercetin diffusion, compared to other different formulation, was good. From this study it was possible to highlight the fundamental role of the Transcutol ${ }^{\circledR} \mathrm{P}$ in increasing the quercetin solubility in the microemulsion and as absortion promoter through the membranes. 